\title{
TEMPORALIZAÇÃO E ESPACIALIZAÇÃO NO JORNAL ON-LINE
}

\section{TEMPORALIZATION AND SPATIALIZATION ON ONLINE NEWS}

Karla Cristina de Araujo FARIA*

RESUMO: Neste artigo serão analisadas as estratégias enunciativas adotadas nos jornais on-line, observando os recursos utilizados na interação entre enunciador e enunciatário inscritos no discurso. Um sujeito é projetado discursivamente sempre a partir de um tempo e de um lugar, por meio de operações enunciativas. Desta forma, percebe-se que as categorias de tempo e espaço são fundamentais na funcionalidade do discurso. Pretende-se observar como as estratégias enunciativas permitem a interação entre os sujeitos aí instalados e as projeções de tempo e espaço, refletindo que efeitos de sentido esta projeção criará nos textos jornalísticos. Para efeito de análise, a versão on-line será comparada com a impressa.

PALAVRAS-CHAVE: Jornal on-line. Temporalização. Espacialização. Enunciação.

ABSTRACT: In this paper, we will analyze enunciative strategies adopted by online newspapers, by observing the

* Docente da FAETEC - Fundação de Apoio à Escola Técnica. E-mail: kcafaria@gmail.com. 
resources used in the interaction between enunciator and enunciatee, which are registered within the discourse. A subject is always discursively projected from a time and a place through enunciative operations. Therefore, we can observe that the time and the space categories are fundamental in the functionality of discourse. In addition, we intend to observe how the enunciative strategies allow the interaction between the subjects who are established in the discourse and the time and space projections, reflecting what meaning effects these projections might create in the journalistic texts. Finally, the online version will be compared to the printed one for the purpose of analysis.

KEYWORDS: Online newspaper. Temporalization. Spatialization. Enunciation.

O espaço é um corpo imaginário, como o tempo é um movimento fictício. Paul Valèry ${ }^{1}$

Valèry, ao reconhecer a qualidade de imaginação e ficção de tempo e espaço, remete ao discurso e aos efeitos de sentido criados para constituir referências temporais e espaciais. Tanto do ponto de vista sintático quanto do figurativo, o tempo e o espaço situam historicamente o discurso, por meio da localização dos momentos e lugares em que transcorrem os acontecimentos.

Neste artigo, serão analisados as projeções de tempo e

1 "L'espace est un corps imaginaire comme le temps un mouvement fictif." VALÉRY, Paul. Tel Quel II. Paris: Gallimard, 1943. 
espaço e os modos de articulação entre as duas categorias, tendo como base a teoria semiótica de linha francesa. 0 corpus de análise é formado a partir, principalmente, de edições do jornal $O$ Globo na sua versão on-line.

\section{Projeções do tempo}

Nos tempos de hoje, no tempo do agora, do já, a evolução tecnológica permite mudanças significativas na busca pela informação. A sociedade contemporânea acelera seus passos, vive intensamente cada minuto e não perde tempo. No tempo do agora não há espaço para o tempo passado, pois se vive tudo simultaneamente, não há futuro também, todos os acontecimentos estão no tempo do presente e é ele que importa. No tempo do já, o homem mostra-se múltiplo e, pela tela do computador, através de janelas virtuais, acessa o e-mail, sua conta corrente, conversa em salas de bate-papo, manda recados em sites de relacionamento, faz compras e se atualiza por meio dos sites de notícias. A internet não só expandiu a noção de espaço, mas também ampliou a de tempo, acelerando-o. Para a geração 2.0, o aparelho é um smartphone que também serve para fazer ligações telefônicas, mas principalmente permite a conexão integral e veloz pela internet. 0 tempo acelerado é fruto da multiplicação de tarefas que cumprimos ao longo do dia, navegando pela multiplicidade de links que percorremos pelo ciberespaço.

Em cada conexão, o homem cria os tempos e espaços das narrativas que produz, reconstituindo, por meio das linguagens, a realidade reconhecida por aqueles que a leem. Para Fiorin (1996, p. 42), "enunciar é criar", o jornal recria, nas suas páginas impressas ou virtuais, o mundo, a partir de um modo 
de articulação que converte o acontecimento em discurso. 0 leitor busca, por meio da tela do jornal on-line, atualizar-se a respeito dos acontecimentos de última hora, como se pudesse dominar aquele que um dia lhe dominará: o tempo.

A categoria de tempo é fundamental na funcionalidade do discurso. Um sujeito é projetado discursivamente sempre a partir de um tempo e de um lugar, por meio de operações enunciativas. Entende-se por enunciação a instância de produção do discurso, e sua concretização é o enunciado. A enunciação é, assim, uma instância abstrata, reconhecível a partir do enunciado e podemos pressupô-la pelas marcas aí deixadas. Segundo Benveniste (1995, p. 82), a enunciação é a “colocação em funcionamento da linguagem por um ato individual de utilização". É o mesmo sujeito que atua na enunciação, na criação, que se instala como simulacro no enunciado e projeta no discurso as categorias de pessoa, tempo e espaço, convertendo, assim, a narrativa em discurso.

Essas projeções se dão por meio de dois mecanismos, a debreagem e a embreagem. A debreagem

é a operação em que a instância de enunciação disjunge de si e projeta para fora de si, no momento da discursivização, certos termos ligados a sua estrutura de base, com vistas à constituição dos elementos fundadores do enunciado, isto é, pessoa, espaço e tempo (FIORIN, 1996, p. 43).

A debreagem pode ser enunciativa, caso seja a projeção da pessoa eu, do tempo agora e do espaço aqui. A debreagem será enunciva no caso da projeção da pessoa ele, do tempo então e do espaço lá. Tais tipos de debreagem produzem diferentes efeitos de sentido. A debreagem enunciativa simula um efeito de subjetividade, pois traz à tona as marcas de $1^{\text {a }}$ pessoa, daquele que enuncia. A debreagem enunciva, mais 
comum nos textos jornalísticos, simula um efeito de objetividade, apagando as marcas do eu no enunciado, criando um efeito de imparcialidade discursiva. 0 sujeito projetado em $3^{a}$ pessoa no enunciado é um observador afastado da cena que narra, simulando a imparcialidade.

As relações de tempo no par então/agora apresentam-se sob a forma da oposição enuncivo vs. enunciativo, produzindo efeitos, respectivamente, de não-concomitância e concomitância com o momento em que se enuncia. 0 par lá/aqui também opõe enuncivo a enunciativo, porém, neste caso, em relação ao espaço de onde se enuncia.

0 que nos interessa aqui é mostrar que efeitos de sentido as projeções de tempo e espaço criam nos textos jornalísticos publicados no jornal on-line. Para tanto, ressaltemos que o tempo a ser analisado é o linguístico, gerado na enunciação por um eu, que fala de algum lugar. Esse tempo pode ser anterior, concomitante ou posterior ao momento da enunciação.

Nos textos jornalísticos publicados no suporte internet, ocorre a simulação de uma homologia entre o tempo cronológico e o tempo do discurso, o tempo dos acontecimentos vividos e o tempo narrado, do que só existe quando enunciado, discursivizado.

\section{Fluxo, simultaneidade, inacabamento}

No jornal impresso há um limite temporal para a entrega da edição a fim de que as máquinas possam imprimir as folhas que o constituem. As notícias dizem respeito a fatos já ocorridos, em geral no dia anterior, possivelmente já relatados na TV e no rádio. 0 jornal impresso precisa de tempo para ser distribuído entre os assinantes e esse intervalo entre o 
acontecimento e sua circulação no jornal cria o efeito de fato ultrapassado, ainda mais considerando-se os meios digitais de divulgação.

Na versão on-line há uma expansão da temporalidade. Nunca uma notícia se dá antes ou depois de um momento de fechamento do jornal, como ocorre nas redações, mas sim ao mesmo tempo, já que sua edição está sendo atualizada constantemente, formando uma sucessão, uma continuidade. No on-line cria-se, portanto, o efeito de simultaneidade com o mundo, de atualidade, como se o passar do tempo da internet fosse o mesmo passar do tempo do mundo e a duração do jornal fosse ininterrupta, como o fluxo contínuo da internet. Isso cria também o efeito de inacabamento.

Na capa das publicações jornalísticas on-line, a referência ao tempo é sinalizada graficamente por meio da descrição da hora pontual. Ao abrir $O$ Globo On-line, abaixo da logomarca do jornal, encontra-se a localização espacial e temporal, o que gera o efeito de sentido de atualização constante da página. $\mathrm{O}$ on-line está em constante transformação, se ocorre um fato, pode-se noticiá-lo de forma imediata, não é necessário esperar o dia seguinte para fazê-lo acontecer. Há a continuidade nos mecanismos de produção e a temporalidade segue em fluxo contínuo, gerando novo efeito, o de atualização. 0 que se busca no on-line é justamente recuperar o tempo do acontecimento e para isso deixam-se reveladas e destacadas as marcas de precisão em relação ao tempo, como, por exemplo, nas seções "Últimas notícias" e "Plantão Rio", nas quais as chamadas das notícias se abrem com a referência de tempo exato, em fonte na cor vermelha. A precisão do registro da hora indica sempre uma pequena diferença em relação ao horário de leitura, mas o efeito de atualização permanece e, com isso, o tempo presente se estende numa duração mais longa 
que a de um instante. Por exemplo, se o leitor abre a tela às $15 \mathrm{~h} 40$ e encontra uma notícia publicada às 15h38, os 2 minutos de diferença não alteram o efeito de atualização, porque o tempo presente compreende esses dois momentos.

Diversos recursos são usados no caso das últimas notícias, para gerar o efeito de simultaneidade e concomitância. 0 jornal Folha de S. Paulo, nas chamadas da seção "Últimas notícias", apresenta um interessante recurso do plano da expressão.

Figura 1 - Print Screen do site da Folha de S. Paulo ${ }^{2}$

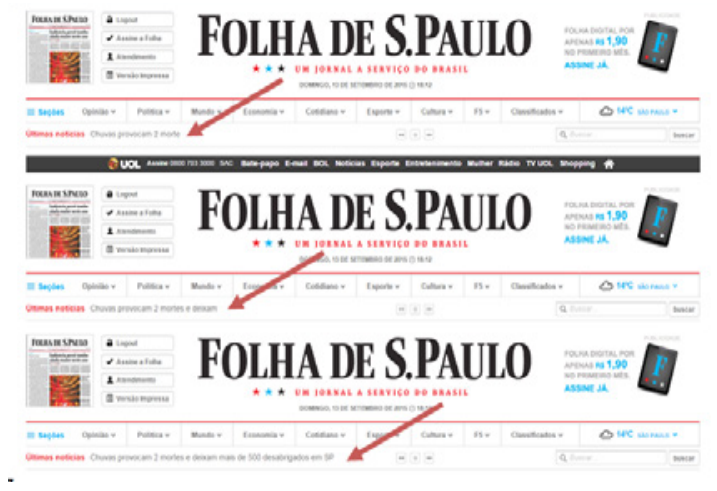

Fonte: Folha de São Paulo

Dentro do banner da seção Últimas notícias, a chamada é construída numa sucessão de letras, como se o enunciador estivesse digitando a chamada naquele momento. Esse movimento das letras cria o efeito de simultaneidade, pois o leitor pensa depreender a informação ao mesmo tempo em que o jornalista a está digitando.

2 Disponível em: 〈http://www.folha.uol.com.br〉. Acesso em: 05 dez. 2015. No conjunto de prints, percebe-se primeiro "Chuvas provocam 2 mortes"/ logo depois, "Chuvas provocam 2 mortes e deixam"/e no último "Chuvas provocam 2 mortes e deixam mais de 500 desabrigados em SP". 
A inclusão da marca temporal precisa colaborar para criar o efeito de concomitância entre o acontecimento e sua divulgação no formato on-line. A precisão da data também aparece no cabeçalho, nos links de notícias e reportagens, deixando claro para o leitor que a redação do on-line é dinâmica: busca, apura e divulga a pauta de forma instantânea.

A formatação dos links de notícias em $O$ Globo On-line segue o mesmo padrão na publicação de todas as notícias: título, legenda, links para Redes Sociais com dados precisos, seguidos do nome do jornalista que apurou a notícia, seguido de seu e-mail e dados de redes sociais. Quando a matéria não é assinada, então, substitui-se o nome do autor por $O$ Globo. E logo abaixo, vem a indicação temporal exata, data e hora:

Figura 2 - Print Screen título de notícia de $O$ Globo $^{3}$

\section{Naufrágio na costa grega deixa ao menos 34 mortos, quatro deles bebês}

Outras 68 pessoas cairam na água, mas foram resgatadas com vida, enquanto 29 nadaram até uma praia POROGLOBO / COM AGÉNCIAS INTERNACIONAIS

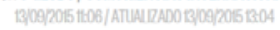

Fonte: O Globo On-line

Deixa-se revelada para o leitor a hora da publicação da notícia e também se informa a hora exata em que ela foi atualizada, criando-se os efeitos de sentido de atualização constante e dinamicidade próprios do veículo na internet. 0 jornal acompanhou o naufrágio e apurou os desdobramentos do acidente. Ao ler a notícia, depois do lide, há links com outras

3 Disponível em: 〈http://oglobo.globo.com/mundo/naufragio-na-costa-grega-deixa-ao-menos-34-mortos-quatro-deles-bebes-17478473). Acesso em: 05 dez. 2015. 
notícias relacionadas com a informação, infográficos e fotogaleria, revelando o processo de apuração dos fatos. Como o tempo linguístico independe do tempo cronológico, os jornais utilizam marcadores temporais que ancoram o tempo linguístico no tempo crônico, mediante, por exemplo, advérbios e a inserção de hora e data.

\section{0 efeito de "ao vivo"}

O Globo On-line apresenta uma seção denominada "Tempo Real" destinada à cobertura "ao vivo" de eventos como partidas de futebol, shows, eleições, trânsito etc. Tal seção busca criar efeitos semelhantes aos do rádio e da TV, ao projetar a transmissão direta de um evento.

Analisando a cobertura de uma partida de futebol, pode-se perceber que há uma narração quase que minuto a minuto do jogo, transformando as jogadas visuais em relato verbal, criando também o efeito de simultaneidade. Na capa do site de $O$ Globo, há uma chamada para que o leitor acompanhe a partida: "Tempo Real - Fla vai vencendo Chapecoense. Acompanhe". Ao clicar no link, o leitor é direcionado em outra aba para a página do site Globo Esporte ${ }^{4}$, pertencente também ao grupo Infoglobo.

4 Disponível em: 〈http://globoesporte.globo.com〉. Acesso em: 05 dez. 2015. 
Figura 3 - Print Screen da seção "Tempo Real" 5

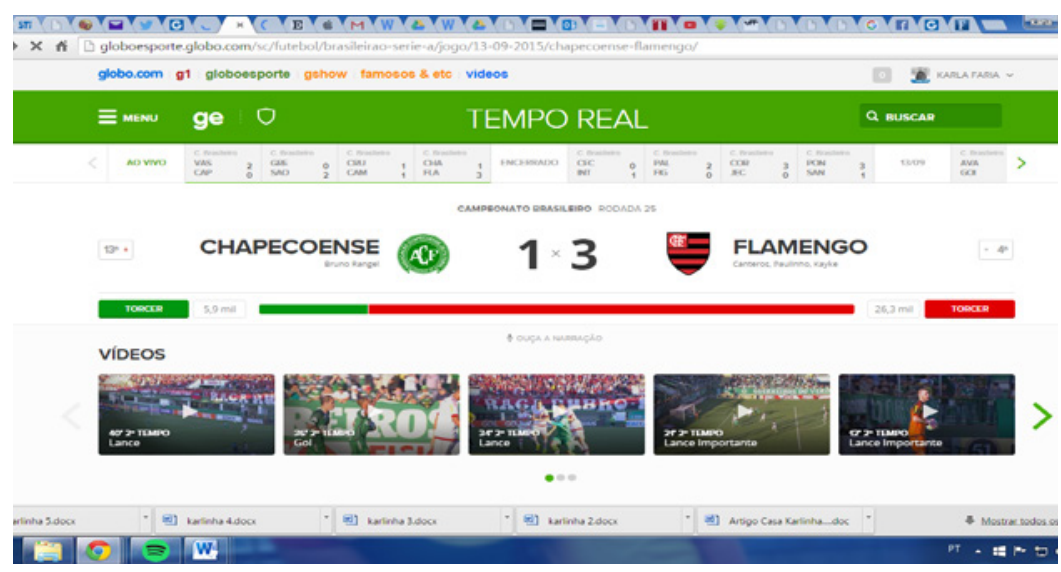

Fonte: Globo Esporte

$\mathrm{Na}$ parte superior da página, abaixo da linha verde "Tempo Real" há a expressão AO VIVO, em verde, destacando os outros jogos que também estão ocorrendo naquele mesmo horário, com a exibição dos placares. 0 leitor pode, se desejar, clicar em outro jogo e acompanha-lo. Na parte central o placar se destaca com os escudos e nomes dos times, com os nomes dos jogadores que fizeram gol e seu posicionamento no campeonato. Abaixo, uma linha fina mostra os números de jogares on-line que estão acompanhando a partida pelo site, em verde os do Chapecoense (5,9 mil) e, em vermelho, os do Flamengo (26,3 mil). Logo abaixo desta linha, centralizado, há um link em cinza "Ouça a narração". Ao clicar ali, o leitor será direcionado para o site da Rádio Globo ${ }^{6}$ e ouvirá a transmissão.

\footnotetext{
5 Disponível em: 〈http://globoesporte.globo.com〉. Acesso em: 05 dez. 2015

6 Disponível em: 〈http://radioglobo.globoradio.globo.com/player/playerAoVivoRJ.htm〉. Acesso em: 05 dez. 2015.
} 
Figura 4 - Print Screen da seção "Tempo Real" 7

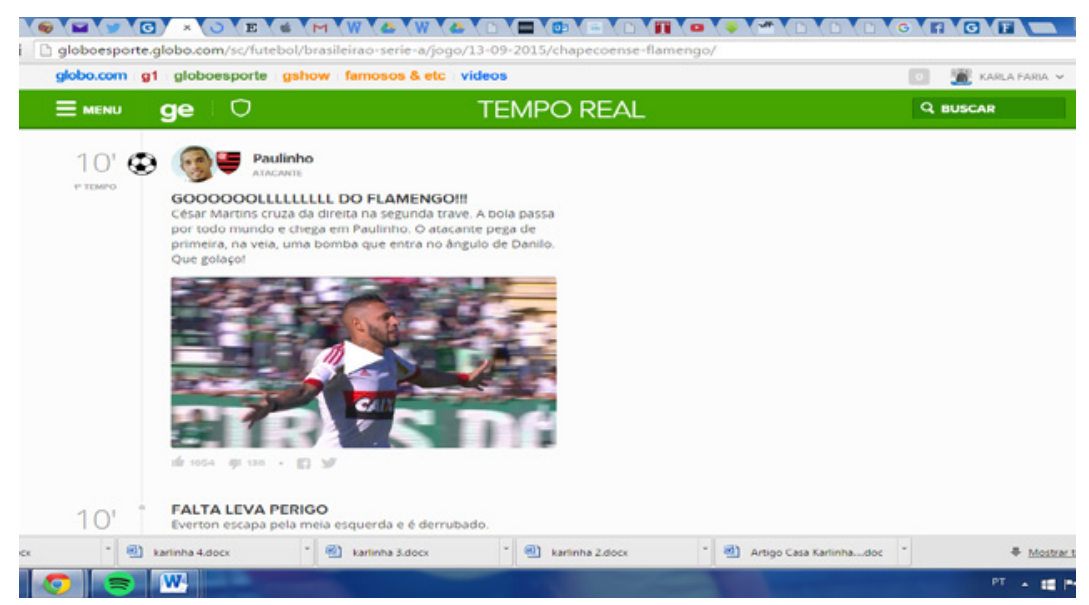

Fonte: Globo Esporte

O objetivo da seção "Tempo Real” é narrar para o enunciatário as jogadas, minuto a minuto, sendo a tela sempre atualizada, com a publicação dos vídeos das principais jogadas, comentários de outros torcedores, informações sobre cartões e substituições. Um alarme sonoro toca quando um time faz gol. 0 internauta pode curtir, comentar e compartilhar os lances nas redes sociais.

É interessante analisar o efeito de sentido criado pelo sintagma "Tempo Real". Na partida de futebol, na verdade, a jogada não é transmitida no momento em que ela acontece, visto que, às vezes, as páginas podem demorar segundos e até minutos para atualizar e carregar as informações, mas, para o leitor diante do monitor, a jogada só terá ocorrido realmente quando o lance aparecer narrado na sua tela. 0 tempo do site não coincide com a transmissão do jogo, ou seja, na

7 Disponível em: 〈http://globoesporte.globo.com/〉. Acesso em: 13 dez. 2015. 
internet, não há a concomitância da transmissão da TV, por exemplo. Segundo Fechine (2008, p. 26), ao discutir a transmissão direta, "trata-se de uma operação que permite a produção, a transmissão e a recepção de um programa de modo simultâneo". Na seção em análise, é preciso que o moderador assista à jogada e depois faça uma espécie de tradução para a linguagem verbal, o que, por mais hábil que seja o moderador, demanda, pelo menos, alguns segundos. A seção "Tempo real" simula o efeito de transmissão direta da TV, mas a relação temporal é distinta, porque há uma pessoa que vê a jogada e a descreve para publicar no suporte digital. Não se caracteriza como uma transmissão direta e sim como uma simulação de transmissão direta, configurando-se como uma situação de transmissão ao vivo. Fechine adverte que

o "ao vivo" é, essencialmente, um fenômeno semiótico: mais que de um procedimento técnico-operacional, a instauração do "ao vivo" na TV depende do modo como os discursos se organizam para produzir determinados efeitos de sentido. Pode-se, portanto, instaurar efeitos de "ao vivo" tanto numa transmissão direta quanto numa gravada. Se por um lado, é possível admitir que toda transmissão direta produz efeito de "ao vivo", não se pode admitir por outro lado, que todo efeito de "ao vivo" seja o resultado de uma transmissão direta (FECHINE, 2008, p. 26).

O enunciador do jornal on-line faz-crer numa transmissão ao vivo, por meio de determinados efeitos ou estratégias discursivas que simulam a simultaneidade. Marcas como o tempo de jogo e o uso dos verbos no presente levam o enunciatário a crer verdadeiramente no discurso.

O termo "real", no título da seção, obedece, assim, a cobranças permitidas pelo meio digital. Comparando a transmissão do evento pela internet com uma transmissão direta 
de TV, percebe-se que os protocolos são diferentes, mas o efeito de simultaneidade, para ambos os enunciatários, é o mesmo e o enunciatário, ainda assim, aceita este fazer-crer como verdadeiro.

No Réveillon, a seção "Tempo real" foi usada como um recurso de cidadania, o jornal informava, em intervalos curtos, como estava o trânsito nas principais vias da cidade, principalmente naquelas em direção à Copacabana. Além do trânsito, fez a cobertura, em pequenos informes, de como estavam as comemorações do Réveillon em vários pontos do Rio de Janeiro.

Figura 5 - Print Screen da seção "Tempo Real” ${ }^{8}$
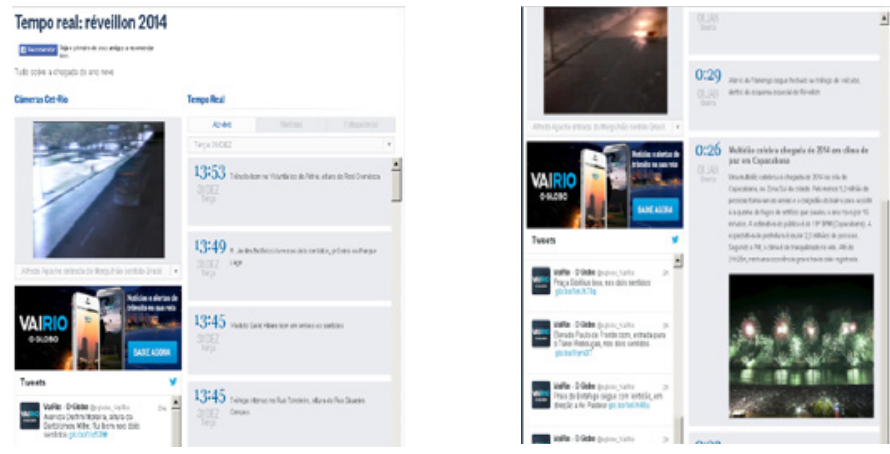

Fonte: O Globo On-line

8 O Globo On-line, 31/12/2013 e 01/01/2014. Figura da esquerda, lê-se 13:53- Trânsito bom na Voluntários da Pátria, altura da Real Grandeza. 13:49- R. Jardim Botânico livre nos dois sentidos, próximo ao Parque Lage. 13:45- Viaduto Saint Hilaire bom em ambos os sentidos. 13:45- Tráfego intenso na Rua Tonoleiro, altura da Siqueira Campos. Na figura da direita: 0:29- Aterro do Flamengo segue fechado ao tráfego de veículos, dentro do esquema especial de Réveillon. 0:26- Multidão celebra chegada de 2014 em clima de paz em Copacabana Uma multidão celebrou a chegada de 2014 na orla de Copacabana, na Zona Sul da cidade. Pelo menos 1,2 milhão de pessoas tomavam as areias e calçadas do bairro para assistir à queima de fogos de artifício que saudou o novo ano por 16 minutos. A estimativa do público é do 19ํㅡㄹ (Copacabana). A expectativa da prefeitura é reunir 2,3 milhões de pessoas. Segundo a PM, o clima é de tranquilidade na orla. Até às $21 \mathrm{~h} 25 \mathrm{~min}$, nenhuma ocorrência grave havia sido registrada. 
Várias marcas ajudam na criação do efeito de ao vivo simulado pelo jornal. Realmente ao vivo, em transmissão direta na seção, o que se tem é a câmera da CET Rio, no lado esquerdo, transmitindo, em tempo efetivamente real, as condições do trânsito no Rio, e oferecendo ao leitor a possibilidade de trocar de bairro ou localidade, por meio de um comando abaixo da imagem. Do lado direito, abaixo da expressão "Tempo Real", há um menu em abas: "Ao vivo", "Notícias" e "Fotogalerias". A aba "Ao vivo" traz a hora exata em algarismos de tamanho grande, na cor azul, e textos curtos e objetivos com as informações sobre a movimentação do trânsito. A seção esteve no ar das $12 \mathrm{~h}$ do dia 31/12/2013 até a madrugada do dia 01/01/2014, fazendo a cobertura integral da movimentação no trânsito e da festa em Copacabana. Essa transmissão em fluxo contínuo imprime ao discurso uma temporalidade contínua, direta, ininterrupta. A referência espacial, as marcas da hora e a transmissão da câmera corroboram o efeito de sentido de ao vivo para o leitor, de simultaneidade, que se associa a um efeito espacial de ubiquidade, como se fosse possível o jornal estar em todos os lugares ao mesmo tempo, informando aos leitores de todos os bairros e cidades do Estado. Essa seção de trânsito não é fixa. Entra no ar quando há um grande acontecimento, ou em ocasiões de feriados, fenômenos naturais, movimento extraordinário na cidade etc. Trata-se de informação de utilidade pública, que aproxima o leitor do jornal.

Relatar os acontecimentos assim que eles aconteciam só era possível pelo rádio e a TV. 0 jornalismo on-line incorpora esse recurso, com a possibilidade de corrigir e emendar a informação dada segundos antes, como se pode verificar nos exemplos a seguir: 
Figura 6 - Print Screen Capas de O Globo On-line
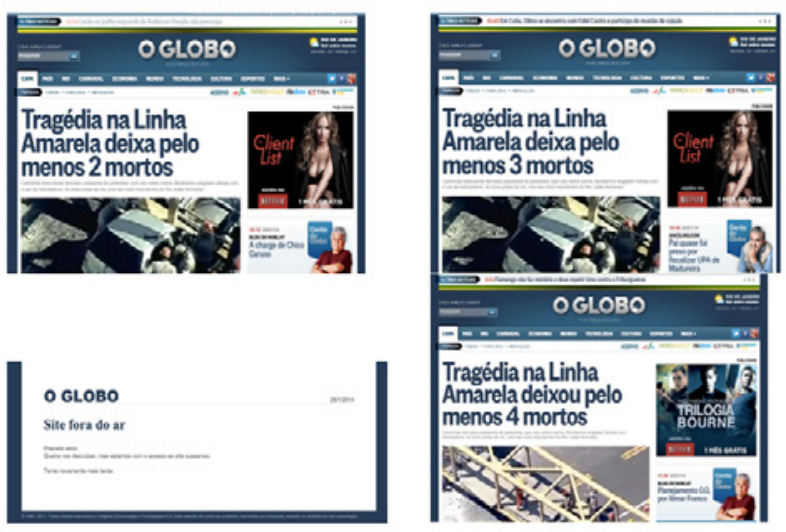

Fonte: $O$ Globo On-line

No dia 28/01/2014, houve um trágico acidente na Linha Amarela, uma das principais vias expressas da cidade, que interliga bairros e municípios vizinhos do Rio de Janeiro. Ao longo do dia, o jornal foi apurando as informações sobre o acidente e atualizando o site com novos dados. A fotografia foi trocada quase $1 \mathrm{~h}$ depois. 0 volume de informações, atualizações e de acesso foi tanto que o site ficou por alguns minutos fora do ar. Para publicar todas as informações, foi necessária a utilização da primeira e segunda rolagens.

\section{Ancoragem e efeitos de sentido}

Para criar o efeito de realidade são utilizados recursos semânticos discursivos que concretizam pessoas, tempo e espaço, produzindo a ilusão de conexão com o real. 0 recurso denomina-se ancoragem:

Compreende-se [como ancoragem] a disposição, no momen- 
to da instância de figurativização do discurso, de um conjunto de índices espaço-temporais e, mais particularmente, de topônimos e de cronônimos que visam a constituir um simulacro de um referente externo e produzir o efeito de sentido de realidade (GREIMAS; COURTÉS, 2008, p. 30).

Nos textos jornalísticos, essa estratégia corrobora o efeito de realidade constitutivo dos gêneros, para fazer o leitor crer no discurso verdadeiro, pois

trata-se de atar o discurso a pessoas, espaços e datas que o receptor reconhece como 'reais' ou 'existentes', pelo procedimento semântico de concretizar cada vez mais os atores, os espaços e o tempo do discurso, preenchendo-os com traços sensoriais que os 'iconizam', os fazem 'cópias da realidade'. $\mathrm{Na}$ verdade fingem ser 'cópias da realidade', produzem tal ilusão. (BARROS, 1990, p. 60).

A ancoragem é realizada por meio de expressões figurativas que o enunciador deixa no texto para o enunciatário. Os elementos da sintaxe discursiva são recobertos pelos procedimentos da semântica discursiva, concretizados em temas e figuras. Segundo Fiorin (1990, p. 64), "tematização e figurativização são dois níveis de concretização do sentido" e são ações que inscrevem os valores no discurso e também o ancoram ideologicamente:

[...] o nível dos temas e das figuras é o lugar privilegiado de manifestação da ideologia. Com efeito, não é nos níveis mais abstratos do percurso gerativo que se manifesta, com plenitude e nitidez, a ideologia, mas na concretização dos valores semânticos" (FIORIN, 1990, p. 75).

No jornal a figurativização contribui tanto para criar o 
efeito de realidade, pois as figuras remetem ao mundo natural, concretizando os fatos noticiados, como também corrobora o efeito de verdade, fundamental no jogo entre o fazer-crer do jornal e o crer do leitor.

Ao longo do dia 31/12/2013, a atualização constante das informações tanto foi mostrando os preparativos para a chegada de 2014 (informações sobre o trânsito das principais vias, a movimentação em Copacabana, local da maior festa de Réveillon da cidade, na seção "Tempo Real") quanto foi criando uma expectativa para a virada do ano:

Figura 7- Print Screen Capas de O Globo On-line ${ }^{9}$

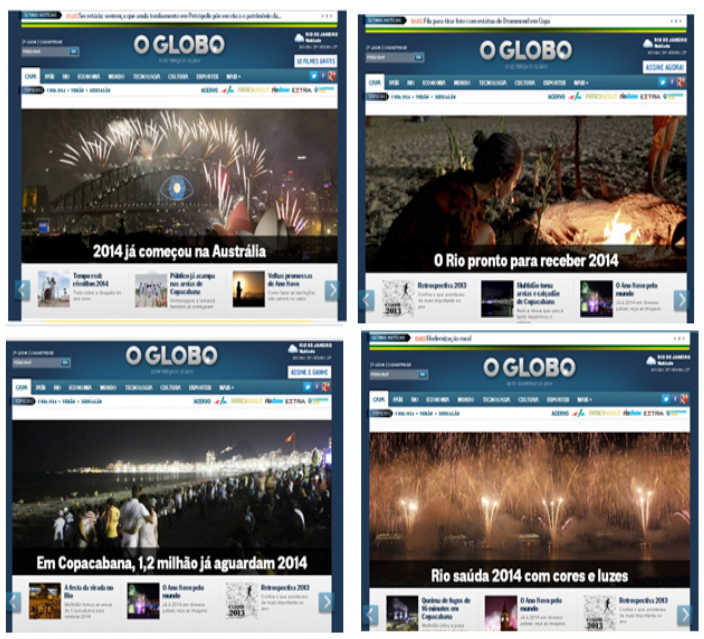

Fonte: O Globo On-line

A manchete de $13 \mathrm{~h} 54$ revela que 2014 já havia come-

9 Print Screen das capas de 0 Globo On-line, 31/12/2014, às $13 \mathrm{~h} 54$ min, às $21 \mathrm{~h} 35$ min e às $22 \mathrm{~h} 56 \mathrm{~min}$, respectivamente, da esquerda superior à esquerda inferior e 0 Globo On-line, 01/01/2014, às 01h $01 \mathrm{~min}$, na direita inferior. 
çado na Austrália. Esta é uma estratégia que se repete nessa data nos jornais on-line, como também nos jornais televisivos: mostrar que o novo ano já é celebrado em outros lugares do planeta. No exemplo em análise, além da expressão numérica 2014, que reafirma a entrada do novo ano, a categoria de tempo fica também explicitada no advérbio "já", que reforça a ideia de concomitância entre o acontecimento e sua divulgação. 0 adjunto adverbial de lugar "na Austrália" localiza espacialmente a ação, dando-lhe o efeito de sentido de realidade, que também é corroborado pela foto de celebração em segundo plano da página. A expressão "já" é repetida outras vezes nesta capa: "Público já acampa nas areias de Copacabana" e "Homenagens a Iemanjá também já começaram". Na reprodução da página, às 22h56, novamente o advérbio é utilizado. 0 advérbio revela a instantaneidade das ações, realizadas na Austrália e em Copacabana, e estes acontecimentos já estão noticiados na página do jornal, simulando os efeitos de ao

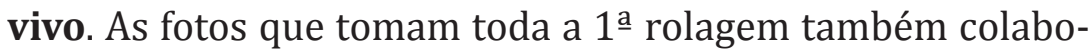
ram para dar concretude ao discurso, mostrando o lugar do acontecimento, Austrália e Copacabana. Além disso, o tema da passagem do ano é figurativizado nas fotos pelos fogos, pela luminosidade, pela celebração que concretizam o tema da festa, trazendo revestimento sensorial. Logo, a repetição de figuras reitera a festa do Réveillon, presentificando o acontecimento para o leitor.

\section{Projeções do Espaço}

As projeções espaciais são utilizadas para reforçar a ideia de atualização temporal constante e também para acentuar os efeitos de sentido de realidade. Assim como as 
categorias de pessoa e tempo, a projeção espacial ocorre no enunciado mediante os mecanismos de debreagem e embreagem. 0 eixo de referência espacial é sempre um aqui, que, quando explicitado, caracteriza uma debreagem enunciativa. Fiorin afirma que

o aqui é o fundamento das oposições espaciais da língua. Esse aqui, que se desloca ao longo do discurso, permanecendo sempre aqui, constitui os espaços do não- aqui. Chega-se, assim, à constatação de que o único espaço inerente à linguagem é o espaço axial do discurso, que é sempre implícito. Ele é que determina os outros (FIORIN, 1996, p. 263).

O enunciador, ao deixar as marcas de espaço no discurso, situa a si e aos demais no espaço. Como sua posição não é fixa e movimenta-se no discurso, o espaço "é reinventado cada vez que alguém toma a palavra, porque, em cada ato enunciativo, temos um espaço novo, ainda não habitado por ninguém" (FIORIN, 1996, p. 263).

Se o aqui define a debreagem enunciativa, o não-aqui caracteriza a debreagem enunciva. A projeção enunciativa gera os efeitos de sentido de aproximação e subjetividade e a enunciva produz os de distanciamento e objetividade.

0 espaço em $O$ Globo On-line é projetado por meio de uma debreagem enunciativa, de um aqui, que corresponde ao espaço do próprio jornal em que se publicam as notícias. Além disso, o espaço do aqui se prolonga na referência geográfica da cidade de publicação, Rio de Janeiro, encontrada na capa, do lado superior esquerdo. As notícias do Rio de Janeiro (aqui ancorado) e do mundo estarão no espaço do aqui, do site. 
Figura 7 - 0 aqui do discurso ${ }^{10}$

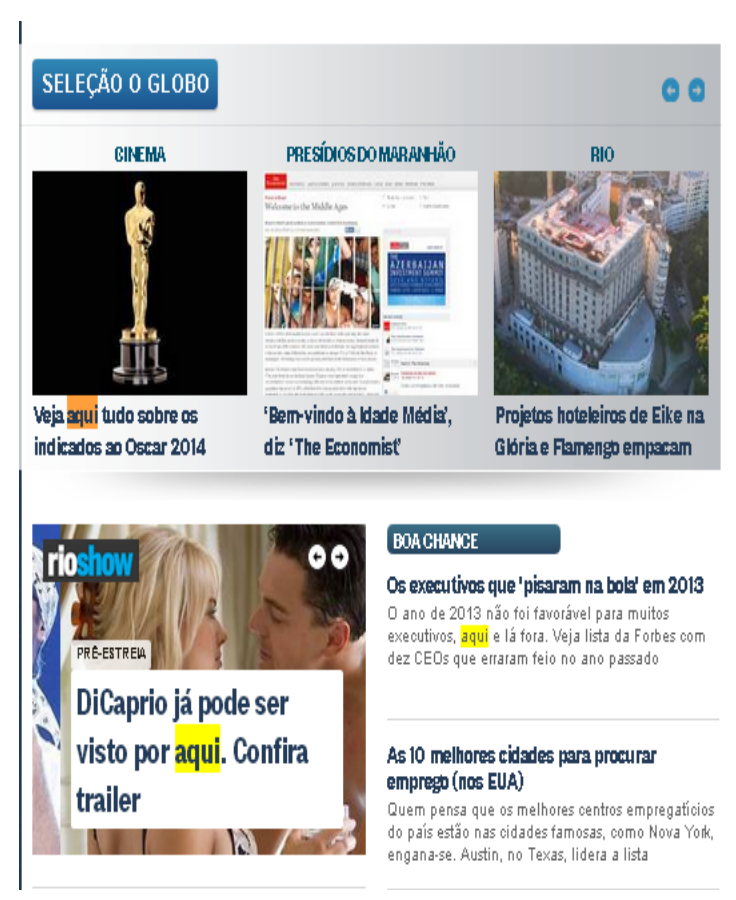

Fonte: O Globo On-line

0 advérbio "aqui" usado nos exemplos reforça o espaço da enunciação, em uma debreagem enunciativa. Em "Veja aqui tudo sobre os indicados ao Oscar 2014", o advérbio aponta justamente para o link do jornal, assim como Em "DiCaprio já pode ser visto por aqui. Confira trailer", referente ao filme que está em pré-estreia. Nesse segundo exemplo, o advérbio se refere ao link, mas pode também referir-se ao fato de o filme já estar passando no Rio de Janeiro. 0 último exemplo revela a oposição entre aqui e lá, prevista na projeção da categoria espacial. Em “O ano de 2013 não foi favorável para muitos

10 O Globo On-line,18/01/2014. 
executivos, aqui e lá fora [...]", os advérbios estão indicando claramente o espaço do enunciador que, numa ampliação geográfica ainda maior, corresponde ao Brasil, por oposição ao lá, que, intensificado pelo advérbio "fora" indica exterior. É no contexto da frase, portanto, que o aqui ganha força figurativa e estende o espaço de onde fala o enunciador.

A internet é concebida na estrutura de rede e sua conexão se dá através de links em forma de hipertexto. 0 jornal on-line é constituído por uma estrutura de links, que constituem a novidade discursiva do meio digital. É relevante considerar o modo como os textos são apresentados e difundidos, pois

hoje estamos cada vez mais conscientes de que o mídium não é um simples "meio" de transmissão do discurso, mas que ele imprime um certo aspecto a seus conteúdos e comanda os usos que dele podemos fazer. 0 mídium não é um simples "meio", um instrumento para transportar uma mensagem estável: uma mudança importante do mídium modifica o conjunto de um gênero de discurso (MAINGUENEAU, 2005, p. 71-72).

O mídium caracterizado por Maingueneau é também chamado de suporte, entendido por Marcuschi (2008, p. 174) "como suporte de um gênero, um locus físico ou virtual com formato específico que serve de base ou ambiente de fixação de um gênero materializado como texto". 0 suporte é, portanto, fundamental para "fixar o texto e assim torná-lo acessível para fins comunicativos" (MARCUSCHI, 2008, p. 175).

Ler no papel é diferente de ler na tela do computador. São suportes diferentes que operam com mecanismos distintos e demandam comandos diferentes do leitor, pois "o modo de transporte e recepção do enunciado condiciona a própria constituição do texto, modela o gênero de discurso" (MAIN- 
GUENEAU, 2005, p. 72).

Considerando, então, uma superposição na definição de suporte, temos o suporte da tela ou do papel, num primeiro nível, e subsequentemente, o jornal considerado ele mesmo como um suporte, diferente, por exemplo, de revistas ou livros. Acresce a essa complexificação da noção, a ideia de que o suporte digital abriga o jornal on-line, suporte de vários gêneros diferentes, da mesma maneira que o suporte do papel acolhe o suporte jornal impresso, em que se manifestam textos também de gêneros variados. Se prosseguirmos numa linha de refinamento de diferenças, teremos diferentes suportes on-line, como o monitor do computador, do laptop, a tela do smartphone, a do tablet etc. Cada suporte e seus consequentes desdobramentos gera ritmo de leitura diferente. É possível ler na tela a versão impressa (denominada de digital ou digitalizada), e para tal foram criadas estratégias que simulam o passar das páginas, como é feito na versão impressa, na tentativa de recuperar o modo de leitura de um meio em outro. A versão on-line apresenta outros recursos próprios da internet que a versão digitalizada, ainda que esteja na tela do computador, no mesmo suporte da versão on-line, não pode oferecer. Nos smartphones a leitura se assemelha à do on-line, mas também é diferente se considerarmos o tamanho da tela, velocidade da internet e do processador ${ }^{11}$. Além disso, $O$ Globo disponibiliza um aplicativo específico para a veiculação das informações, apresentando uma formatação mais condensada da versão on-line, com recursos mais específicos de acordo com o modelo do aparelho:

110 acesso ao site de notícias de $O$ Globo pelo celular se dá por http://moglobo.globo.com/, e o próprio site informa que "o conteúdo será sempre o mesmo. Mas as diferenças de proporção das telas, os programas de navegação e os sistemas operacionais variados podem resultar em aparências ligeiramente diferentes entre os sites". Disponível em: 〈http://oglobo.globo.com/mobile/sitenocelular.asp〉. Acesso em: 06 dez. 2015. 
Figura 8 - Print Screen Capa de O Globo On-line ${ }^{12}$

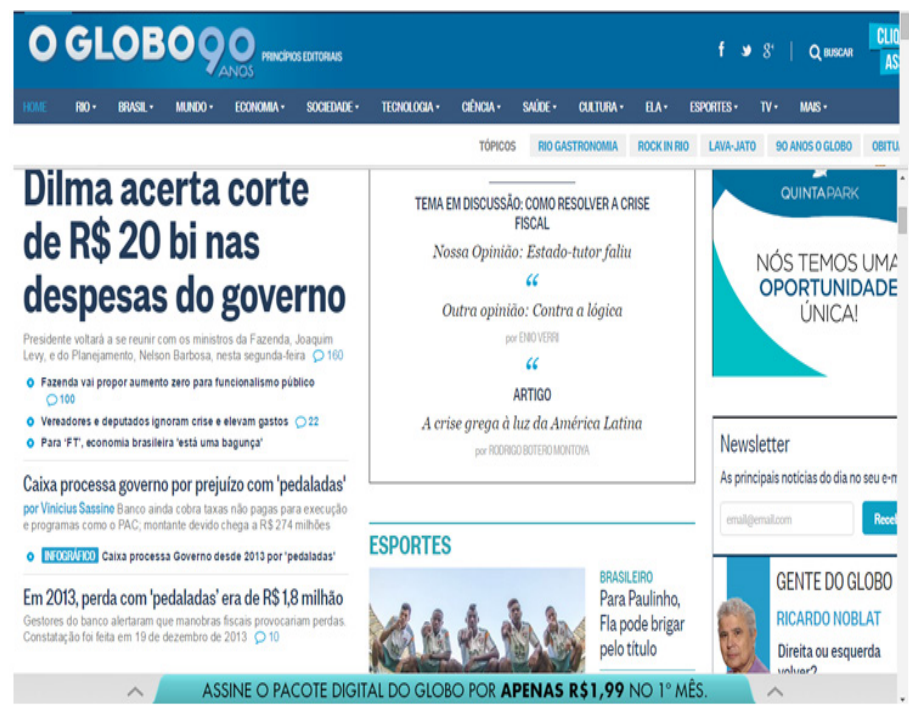

Fonte: O Globo On-line

12 O Globo On-line, 27/01/2014. 


\section{Figura 9- Print Screen Capa de $O$ Globo Digital $^{13}$}

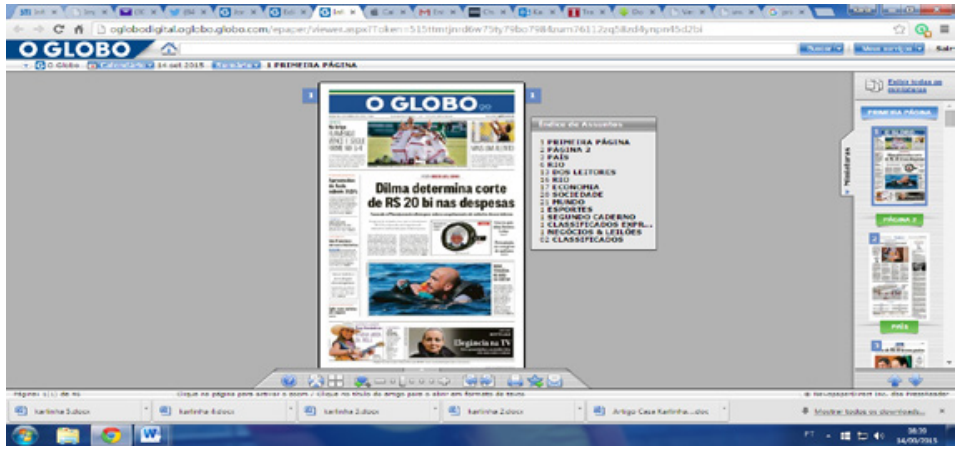

"Fonte: O Globo Digital"

\section{Figura 10 - Print Screen Capa do aplicativo O Globo Notícias ${ }^{14}$}

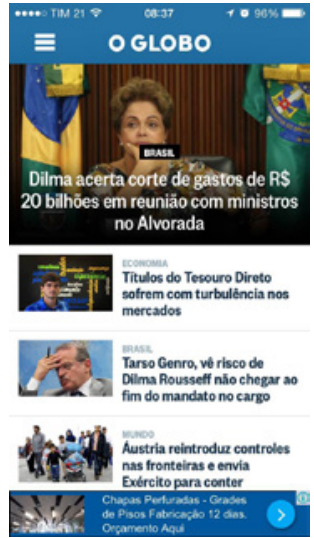

Fonte: $O$ Globo Notícias

13 O Globo Digital, 27/01/2014. Disponível em: 〈https://www.oglobodigital.com.br/〉. Acesso em: 06 dez. 2015.

14 Aplicativo 0 Globo Notícias, versão IOS, sistema operacional desenvolvido pela Apple para seus aparelhos móveis como Iphone, Ipad e Ipod. A interface do usuário é baseada no conceito de manipulação direta, utilizando gestos em multi-toque. A interação com o sistema operacional inclui gestos como apenas tocar na tela, deslizar o dedo, e o movimento de "pinça" utilizado para se ampliar ou reduzir a imagem. Disponível em: ‘http://oglobo.globo.com/mobile/sitenocelular.asp». Acesso em: 06 dez. 2015. 0 aplicativo 0 Globo notícias também é disponibilizado para celulares compatíveis com o sistema Android. 
Cada suporte determina os diferentes modos de leitura e interfere na noção de espaço, uma vez que o aqui do lugar em que se publica muda de configuração, de modos de produção e de leitura, e ancora figurativamente o espaço do enunciador em diferentes materialidades. No jornal on-line, a partir da capa, o leitor se movimenta pelos links e o clique do internauta substitui o movimento das mãos do leitor que vira as páginas do impresso. As idas e vindas do leitor pelo site do jornal são de sua escolha, mas o jornal cria estratégias manipuladoras para cercar o leitor de uma possível saída de seu espaço. 0 link de uma notícia específica sempre traz o link de outras do mesmo interesse, da mesma editoria, e o leitor, muitas vezes, é guiado por essas sugestões do enunciador. A configuração fixa na parte superior do site de $O$ Globo On-line permite claramente que o leitor volte à capa assim que desejar ou acesse as principais editorias do jornal no menu fixo na parte superior. Todos os recursos do hipertexto conduzem o leitor para esta navegação interna entre as páginas do site. Entretanto, o próprio site apresenta links externos que levam o leitor para outros espaços, para a exterioridade do jornal. Links da própria empresa Infoglobo, como Globo.com, das redes sociais, da rádio $C B N$ e também os de publicidade levam o leitor para uma área externa, abrindo uma nova aba ou janela no navegador. Esta é uma estratégia interessante, uma vez que o novo site não se sobrepõe à página do jornal. 0 acesso ao exterior gera um movimento mais extenso de abertura de uma nova aba ou janela ${ }^{15}$, acessível em outro espaço que não fecha o do jornal, como se tivéssemos um aqui e um lá coe-

15 O Globo On-line está configurado automaticamente para a abertura de links internos de forma sobreposta, um link se abre no lugar do anterior, mas para sites externos, abre-se uma nova aba ou janela, de acordo com a configuração dos navegadores, programas de acesso ao conteúdo da internet. 
xistindo no mesmo espaço, tanto se considerarmos a noção de suporte quanto se levarmos em conta a questão do espaço discursivo figurativizado.

Em algumas notícias, o leitor pode encontrar a indicação de um link externo que seja parte da informação ali contida. Por exemplo, nas notícias sobre o Sisu de 2014, geralmente, havia um link na própria notícia que direcionava o leitor para o site do Sisu alocado no MEC, que era aberto em outra aba ou janela do navegador. Na cobertura das Eleições, além de noticiar o movimento dos eleitores, em espaços diversos, o jornal acompanhou juntamente com o TRE o resultado das eleições. Em 2010, coube ao site compartilhar a repercussão da vitória de Dilma Rousseff em outros países, neste caso, o $O$ Globo On-line reproduziu em sua capa a do jornal espanhol El País, criando um maior efeito de verdade.

Figura 11 - Print Screen Capa de O Globo On-line ${ }^{16}$

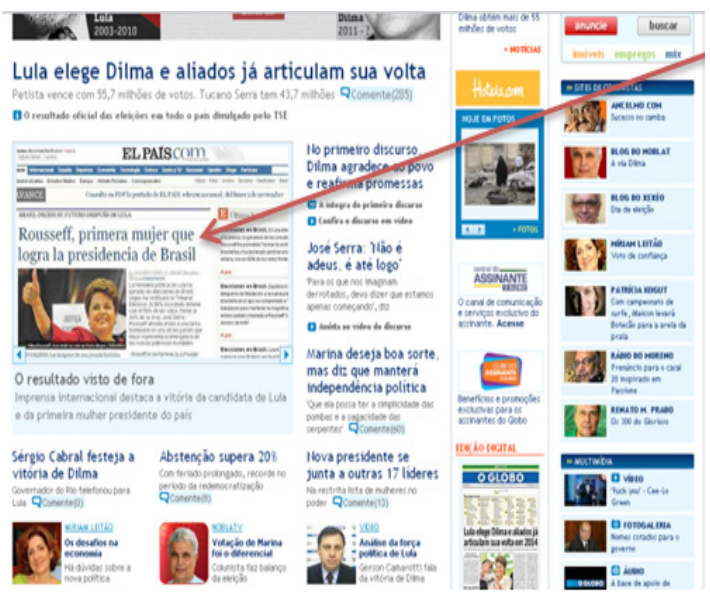

Fonte: O Globo On-line 
Ao clicar no link da página de $O$ Globo On-line, o leitor era direcionado para a capa de El País, revelando que o jornal brasileiro não só noticiou a eleição, mas também mostrou a repercussão da eleição brasileira no país e no mundo. Isso mostra a multiplicidade de informações do meio jornalístico e a dinamicidade para apurar e divulgar as informações. 0 jornal gerou um movimento que trouxe o lá, do jornal espanhol, para o aqui enunciativo. E ao mesmo tempo, proporcionou o deslocamento do leitor para o lá, espaço do El País.

Figura 12 - Print Screen Capa de El País ${ }^{17}$

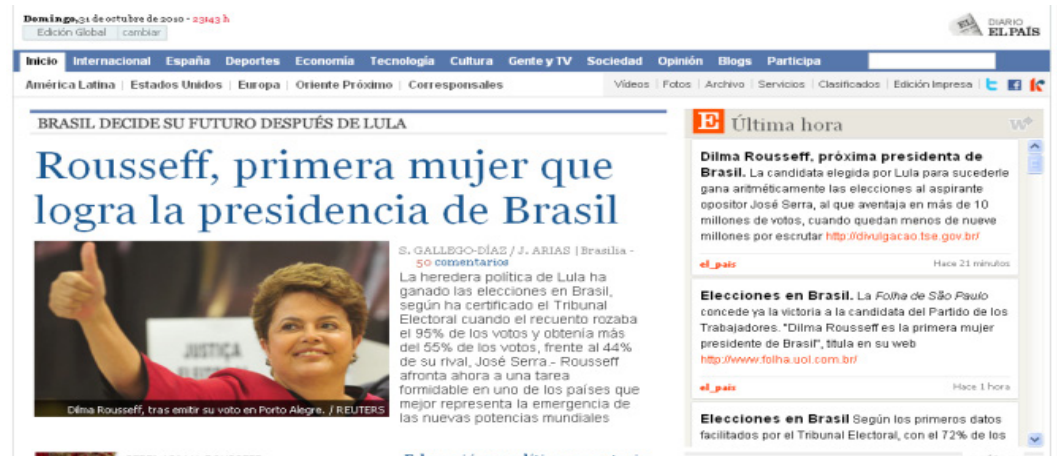

Fonte: El País

O jornal $O$ Globo On-line não apenas acompanhou a apuração, mas fez a cobertura do dia da eleição nas principais cidades do país e deu repercussão ao resultado aqui e no exterior, simulando estar em todos os lugares ao mesmo tempo, uma outra característica do jornalismo on-line, como nos lembra a campanha publicitária de $O$ Globo: Online. On time,

17 El País (edição Global). Disponível em: 〈http://elpais.com/elpais/portada_america. html〉. Acesso em: 06 dez. 2015. 
full time ${ }^{18}$. A noção de ubiquidade, assim, institui o que Zilberberg (2010) chama de "objetos enriquecidos e exaltantes, em suma, superlativos". A cultura do excesso, da superposição de acontecimentos e da sobreposição de elementos (sejam eles linguagens ou páginas, códigos ou links) associa tempo e espaço, como categorias sintáticas ou como figurativizações discursivas, numa perspectiva em que o objeto, "por força de sua desproporção, se apodera do sujeito" (ZILBERBERG, 2010).

Na seção "Tempo Real" sobre trânsito (vista anteriormente), há links com câmeras da CET- Rio e do Centro de Operações da Prefeitura do Rio. Na página, são retransmitidas as imagens das câmeras espalhadas pelos pontos do Rio de Janeiro. Essas imagens não são produzidas pelo jornal. Por meio de sistemas de tecnologia permitidos pelo suporte, o jornal se utiliza de imagens geradas por um órgão público para criar o efeito de ao-vivo e dar mais efeito de credibilidade e verdade à informação. Ainda na seção "Tempo Real" sobre as partidas de futebol a estratégia de transferir o leitor a outro site também acontece, ainda que seja do mesmo grupo, o acompanhamento dos lances da partida não é mais nos links do jornal $O$ Globo e sim do site Globo Esporte. Ainda que não seja o espaço do jornal, o leitor sente-se seguro, pois o site tem a chancela do grupo Infoglobo, reafirmando a credibilidade da informação. Os links de publicidade, geralmente exibidos em movimento, são outro exemplo de estratégias que levam o leitor a superpor tempos e espaços, que podem levar à dispersão ou ao retorno à página do jornal.

18 O slogan da campanha publicitária do jornal O Globo lançada em setembro de 2008, que simula noticiar toda hora em todos os lugares. 


\section{Estratégias de ancoragem}

A fotografia no jornal contribui para a concretização de lugares, fatos e acontecimentos, como imagens que reforçam a ilusão de realidade.

As fotografias - fruto de um aparato tecnológico- figurativizam iconicamente o espaço. Segundo Lucia Teixeira:

A iconicidade costuma estar associada à saturação de traços figurativos que busca aproximar a representação (feita por meio de uma pintura, uma fotografia, um texto verbal, etc) de uma imagem do mundo (TEIXEIRA, 2001, p. 416).

O procedimento de figurativização tenta recobrir ao máximo a realidade, quanto mais icônico, maior é o efeito de realidade obtido, pois "na fotografia a figuratividade remete a figuras do mundo natural, facilmente reconhecíveis, própria à iconicidade deste tipo de linguagem" (GOMES, 2008, p. 63).

Figura 13 - Print Screen Capa de O Globo On-line

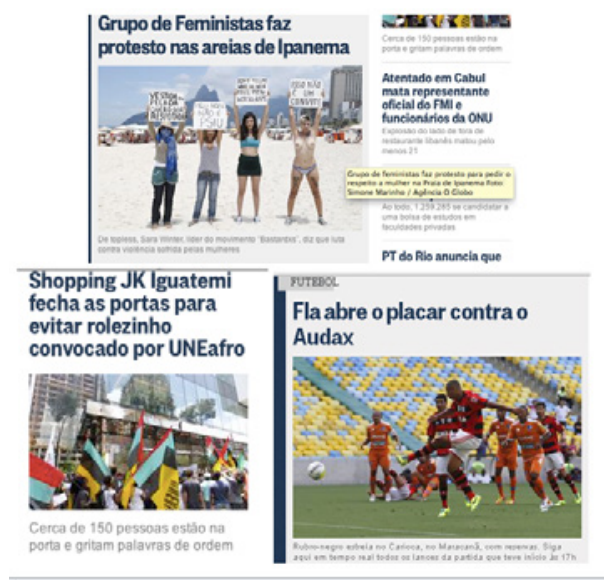

Fonte: O Globo On-line 
As fotos em análise figurativizam o espaço destacado pelo verbal das notícias da capa. São duas notícias que fazem referência a protestos e as fotografias mostram o flagrante do acontecimento concretizando os espaços: as feministas em Ipanema e os manifestantes em frente ao Shopping JK Iguatemi. A fotografia da partida de futebol apreende um instante do jogo que está acontecendo naquele momento, é uma chamada para a seção "Tempo Real" que acompanhava o jogo do Campeonato Carioca. As imagens reafirmam a realidade, pois foram capturadas nos espaços onde os acontecimentos ocorriam e foram trazidas para a tela. 0 lá - o exterior - foi inserido no aqui - espaço do enunciador - aproximando ainda mais o enunciatário do acontecimento. Diana Luz Pessoa de Barros destaca a importância das fotos, pois "o papel ancorador da fotografia [...] é assegurado pela crença ideológico-cultural no seu caráter de 'cópia do real'". (BARROS, 1990, p.61). No jornal, a publicação da foto é também uma estratégia de argumentação fundamental, pois

funciona [...] como uma espécie de persuasão veridictória, uma garantia de fidelidade a um certo mundo real, concreto, dado. [...] [A fotografia] é tomada, por quem a observa, como documento, expressão de realidade, verdade, portanto (TEIXEIRA, 2001, p. 416).

Além do efeito de realidade, o enunciador, por meio dessa estratégia, simula estar em todos os lugares ao mesmo tempo, cobrindo todos os fatos. Para criar o maior efeito de realidade, ao passar o mouse pela fotografia, abre-se uma pequena janela com o título da reportagem e o nome da fotógrafa.

Os exemplos analisados anteriormente, da retransmissão das câmeras da CET-Rio e da cobertura do acidente na Linha Amarela, no Rio de Janeiro, (p.71), também demonstram 
que esta estratégia cria o maior efeito de realidade e de atualização, próprios do meio on-line. 0 que se observa é que há uma movimentação entre espaços, levando a informação em transmissão direta para o leitor, reforçando a ideia de que se transmite a informação simultaneamente a seu acontecimento. Esta estratégia confirma a ideia do entrelaçamento do tempo e do espaço como estratégia de fazer-crer, fundamental no jornalismo para gerar o efeito de sentido de veridicção.

\section{Deslocamentos espaciais}

A disposição espacial dos elementos da capa do jornal on-line (1ํㅡㅁ página) é alterada ao longo dia. Uma notícia que era manchete em um determinado momento é substituída por outra notícia mais atual, então, aquela é realocada como uma chamada. As chamadas também mudam de posição, da esquerda para a direita, de cima para baixo. 0 caráter dinâmico destes deslocamentos gera um movimento neste espaço que simula a ideia de instantaneidade da informação e de grau de importância do fato noticiado. Há momentos em que não há notícias novas na tela, mas a reorganização das chamadas cria o efeito de sentido de atualização constante previsto pela temporalidade estabelecida pelo suporte. Então, percebe-se que nem sempre o site está com novas informações, entretanto a nova disposição dos elementos da capa é uma estratégia visual do PE, relacionada aos elementos espaciais, que leva o enunciatário a crer na atualização recorrente.

Assim como na projeção temporal, a ancoragem espacial deixa reveladas no enunciado as marcas que geram o efeito de realidade e também de verdade do texto jornalístico. Um acontecimento ocorre em um determinado momento e 
em um determinado lugar. Os advérbios e adjuntos adverbiais indicam onde os acontecimentos ocorreram, criando a referencialização para o leitor:

Quadro - Notícias veiculadas no Jornal

"No Brasil, 284 pessoas morreram este ano vítimas da H1N1"19

"Dilma está em Nova York para abrir assembleia da ONU"20

"Primeiro lugar de medicina na UFRJ tirou 1000 na redação e gabaritou a prova de Português" ${ }^{21}$

"Grupo promove correria no Plaza Shopping, em Niterói" 22

Fonte: O Globo On-line

Os exemplos, transcritos de datas diferentes, mostram que a estratégia da ancoragem espacial situa os acontecimentos em um determinado espaço. Na língua, geralmente, um alguém faz uma ação, em um determinado momento, em um determinado lugar. A indicação do espaço, normalmente, é alocada no final da informação, mas, num recurso próprio da sintaxe do discurso verbal, pode aparecer primeiro, como forma de destacar a informação. No primeiro exemplo, a expressão "no Brasil" foi topicalizada, realçando o fato de que

19 O Globo On-line, 19/08/2012.

20 O Globo On-line, 23/09/2012.

21 O Globo On-line, 13/01/2013.

22 O Globo On-line, 18/01/2013. 
as mortes ocorreram no país. 0 segundo exemplo destaca que a presidente Dilma está "em Nova York", com a finalidade de abrir a assembleia da ONU. No terceiro, a informação "na UFRJ" é tão importante quanto o fato de o menino ter ficado em primeiro lugar. Ficar em primeiro lugar tem mais peso na relação com a informação, por ter sido resultado da disputa por uma vaga no curso de medicina, em uma das universidades mais renomadas do país. E o último exemplo apresenta dois marcadores espaciais, "no Plaza Shopping", "em Niterói". 0 primeiro marcador refere-se ao local onde o fato ocorreu, o adjunto adverbial "em Niterói" precisa a informação, mostrando a cidade onde fica o shopping. Os exemplos selecionados simulam o efeito de realidade pretendido pelo texto jornalístico, gerando a credibilidade da informação.

Tanto em relação ao papel dos marcadores sintáticos quanto pela mobilidade das notícias no espaço físico do suporte, no jornal on-line ocorre a expansão da espacialidade. 0 jornal impresso tem o limite do papel cortado em formato tabloide ou standard ${ }^{23}$ ficando, neste caso, limitado pelo espaço da página de papel, enquanto o jornalista do on-line não teme esse limite. As notícias do on-line apresentam configuração textual muito semelhante à da versão impressa, entretanto, é possível ampliar as informações tanto na própria notícia como também na inserção de outros hiperlinks, com outras informações e com imagens, vídeos e conectando esta notícia a outras.

\section{Conclusão}

O fluxo de leitura da notícia segue um ritmo diferente

23 Os jornais brasileiros são impressos em dois formatos: standard, 55 X $29 \mathrm{~cm}$ e o tabloide, $26 \times 29 \mathrm{~cm}$. 0 mais usado no Brasil é o formato standard. 
do jornal impresso porque, ao longo da leitura, há a possibilidade de um movimento de dispersão ou de aprofundamento da informação. 0 fluxo é interrompido, atravessado por outras possibilidades de leitura, que desconcentram o leitor, ou fazem com que se concentre numa notícia particular, abandonando a página principal de onde partiu. Instalam-se duas lógicas de leitura, a da fragmentação e a do aprofundamento, articuladas pelos procedimentos de temporalização e espacialização.

As estratégias sintáticas de projeção de tempo, por meio de mecanismos enunciativos, de debreagem ou embreagem, e as estratégias de simulação de ao vivo presentificam o acontecimento para o leitor, inserindo-o neste fluxo contínuo de temporalidade instaurado pelo jornal, que corrobora o efeito de realidade e, ao mesmo tempo, acolhe a subjetividade do compartilhamento do tempo com o leitor, recursos próprios do fazer jornalístico.

As projeções espaciais, também analisadas, são igualmente utilizadas para reforçar a ideia dessa interação e para acentuar os efeitos de sentido de realidade. Verificaram-se três modos de considerar a espacialidade: nas projeções sintáticas, em que o jogo entre o aqui enunciativo e o lá enuncivo põe em relação os efeitos de subjetividade e objetividade; nas coberturas figurativas, que concretizam, sobretudo com o mecanismo da ancoragem, particularmente com o recurso da fotografia, a ilusão de realidade; e na relação com o próprio suporte, que estabelece coerções para o material publicado e propõe formas próprias de interação com o leitor, por meio dos recursos hipertextuais.

Os recursos disponibilizados pela internet constituem um novo modo de fazer notícia, o da notícia se fazendo, do repórter buscando o desdobramento dela no ar, na rede, da 
correção imediata, do acréscimo contínuo, configurando uma colagem maior do jornal com a incompletude do mundo.

\section{REFERÊNCIAS}

BARROS, D. L. P. Teoria semiótica do texto. São Paulo: Ática, 1990.

BENVENISTE, E. Problemas de linguística geral I. Trad. Maria da Glória Novak e Maria Luisa Neri. Campinas: Pontes: Ed. da Unicamp, 1995.

FECHINE, Y. Televisão e presença. Uma abordagem semiótica da transmissão direta. São Paulo: Estação das Letras e das Cores, 2008.

FIORIN, J. L. Elementos de análise do discurso. São Paulo: Contexto, 1990.

FIORIN, J. L. As astúcias da enunciação: as projeções de pessoa, tempo e espaço no discurso. São Paulo: Ática, 1996.

GOMES, R. S. Relações entre linguagens no jornal: fotografia e narrativa verbal. Niterói: EdUFF, 2008.

GREIMAS, A. J.; COURTÉS, J. Dicionário de Semiótica. Trad. Alceu Dias Lima et al. São Paulo: Contexto, 2008.

MAINGUENEAU, D. Análise de textos de comunicação. Trad. Cecília P. de Souza-e-Silva e Décio Rocha. São Paulo: Cortez, 2005. 
MARCUSCHI, L. A. Produção textual, análise de gêneros e compreensão. São Paulo: Parábola Editorial, 2008.

TEIXEIRA, Lucia. Relações entre o verbal e o não-verbal: pressupostos teóricos. In: VII Caderno de Discussão do Centro de Pesquisas Sociossemióticas. São Paulo: CPS, 2001.

ZILBERBERG, C. Observações sobre a base tensiva do ritmo. Trad. Lucia Teixeira e Ivã Lopes In: Estudos semióticos, v.6, n.2, p.1-13, nov, 2010. Disponível em: 〈http://www.fflch.usp. br/dl/semiotica/es/eSSe62/2010esse62_czilberberg.pdf). Acesso em: 05 dez. 2015.

Artigo recebido em setembro de 2015 e aprovado em dezembro de 2015.

Disponível em: http://seer.fclar.unesp.br/casa 